\title{
Advances in Architectural Geometry (AAG) 2016 Symposium
}

\author{
Orkun $\operatorname{Kasap}^{1}$ (D)
}

Published online: 10 February 2017

(C) Kim Williams Books, Turin 2017

\begin{abstract}
The Advances in Architectural Geometry (AAG) symposia serve as a unique forum where developments in the design, analysis and fabrication of building geometry are presented. With participation of both academics and professionals from the fields of architecture, engineering, computer science and mathematics, each symposium aims to gather and present practical work and theoretical research that responds to contemporary design challenges and expands opportunities for architectural form. This report summarizes the AAG2016, the fifth edition of the symposia hosted by the Swiss National Centre of Competence in Research (NCCR) Digital Fabrication at ETH Zurich from 9 to 13 September 2016.
\end{abstract}

Keywords Architectural geometry · AAG symposium · Computational design $\cdot$ Structural design $\cdot$ Form-finding $\cdot$ Digital fabrication

Geometry has always been an essential part of architectural design. However, the introduction of computation to architectural design has opened up a whole world of new forms and geometrical constellations to be explored by designers. The last three decades saw computation slowly become indispensable to architectural design. Simultaneously, free-form architecture has begun to move from virtual environments to actual construction sites with architects around the world implementing projects which make use of non-standard geometries. At the same time, complications in the fabrication and assembly processes of building components with such non-standard geometries proved that advanced computational design

Orkun Kasap

kasap@arch.ethz.ch

1 ETH Zurich/NCCR Digital Fabrication, HIB E 25/Stefano-Franscini-Platz 1, 8093 Zurich, Switzerland 
strategies are needed if these geometries are to be accurately and efficiently transferred to the real world. As most of the knowledge and skills required for the development of such strategies fall outside the architects' area of expertise, interdisciplinary collaboration between architects, engineers, computer scientists and mathematicians becomes essential.

The Advances in Architectural Geometry symposia series, the first edition of which was organised in 2008 by Helmut Pottmann, focuses on the theoretical and practical developments of a scientific nature within the interdisciplinary field of architectural geometry. The host to AAG2016 was the NCCR Digital Fabrication, a leading research initiative which focuses on the development and integration of digital technologies within the field of architecture. The NCCR Digital Fabrication promotes intense cross-disciplinary research amongst the disciplines of architecture, structural design, materials science, computer science, control systems engineering, and robotics. The focus on interdisciplinary collaboration of both the NCCR Digital Fabrication and the AAG symposia series enabled strong synergies to emerge, especially as a result of the strong participation of the NCCR Digital Fabrication's researchers and students in the AAG workshops and conference activities.

The AAG2016 comprised two days of hands-on workshops (September 10-11) followed by two days of conference activities (September 12-13) featuring presentations by the authors of 22 peer-reviewed papers, four keynote lectures, a poster forum and a parallel exhibition.

The call for workshop proposals was met with great interest. The symposium organisers received more than 20 proposals from leading companies and experts from renowned institutions in the field. Dave Pigram, workshop chair of the AAG2016 symposium, selected eleven of these for implementation. During the workshops, over 140 participants had the chance to engage with state-of-the-art, bespoke analysis, design and fabrication methods and tools, and exchange valuable know-how. Panagiotis Michalatos and Andrew Payne from Autodesk led the workshop "Voxel Formations" which investigated workflows designed to produce structurally optimised architectural elements with metal additive manufacturing, using Autodesk's Monolith, a voxel-based modelling editor. Participants learned how to design parts that are optimised according to functional criteria and to incorporate internal structural patterns that aid in their overall performance. Another well-attended workshop was "Calibrated and Interactive Modelling of Form-Active Hybrid Structures" led by Anders Holden Deleuran, Daniel Piker, and Cecilie Brandt-Olsen. During this course, participants took a close look at the structural and computational design process of coupling two or more different structural elements with low stiffness, such as slender beams, cables or membranes, into one structural assembly of high stiffness, offering high load-bearing capacity.

Thanks to the NCCR Digital Fabrication's core competency and robotic infrastructure at ETH Zurich, the AAG2016 also featured several workshops on digital fabrication. Shajay Bhooshan, Vishu Bhooshan, David Reeves, Ilya Pereyaslavtsev, and Alicia Nahmad led the workshop "Freeform Developable Spatial Structures" which focused on the algorithmic exploration of structural topologies that are realised through the employment of a variety of materials and robotic fabrication methods. Another cluster with exciting output was "Force- 
Adaptive Hot-Wire Cutting" led by David Jenny and Romana Rust. Their workshop focused on the expanded geometric possibilities offered by Spatial Wire Cutting (SWC). Participants investigated a range of SWC surface typologies and robotically fabricated them as full-scale polystyrene elements (Fig. 1).

After two intense days of practical work, the AAG2016 conference took place. The morning session on the first day of the conference was chaired by Mark Pauly and highlighted advances in the computational modelling, analysis, and optimisation of complex surface geometries for improved efficiency and accuracy in their application to architecture. Elissa Ross and Robert Aish demonstrated new methods for rationalising the physical realisation of meshes with equal depth as constructible structures. The following session, chaired by Benjamin Dillenburger, featured projects introducing novel modes of construction which utilise computation for improved assembly techniques. Christopher Robeller introduced a system which uses integral through-tenon joints for a fast, precise and simple assembly of doublycurved lightweight shells, built from interconnected wood veneer plates (Fig. 2).

Martin Self demonstrated an alternative approach to the common practice of digitally designing and fabricating non-standard building components for the building of complex architectural geometries. This method actively exploits the inherent geometric forms of non-standard materials, such as near-site forked wood, by applying 3D-scanning, parametric control modelling, and robotic fabrication to form a Vierendeel-style arching truss (Fig. 3).

The last session of the first conference day was chaired by Sigrid Adriaenssens and focused on novel design and assembly techniques of bent shells and tensegrity structures. Riccardo La Magna presented how they produced a given shape with doubly-curved surfaces by form-conversion and by informing the structure of the

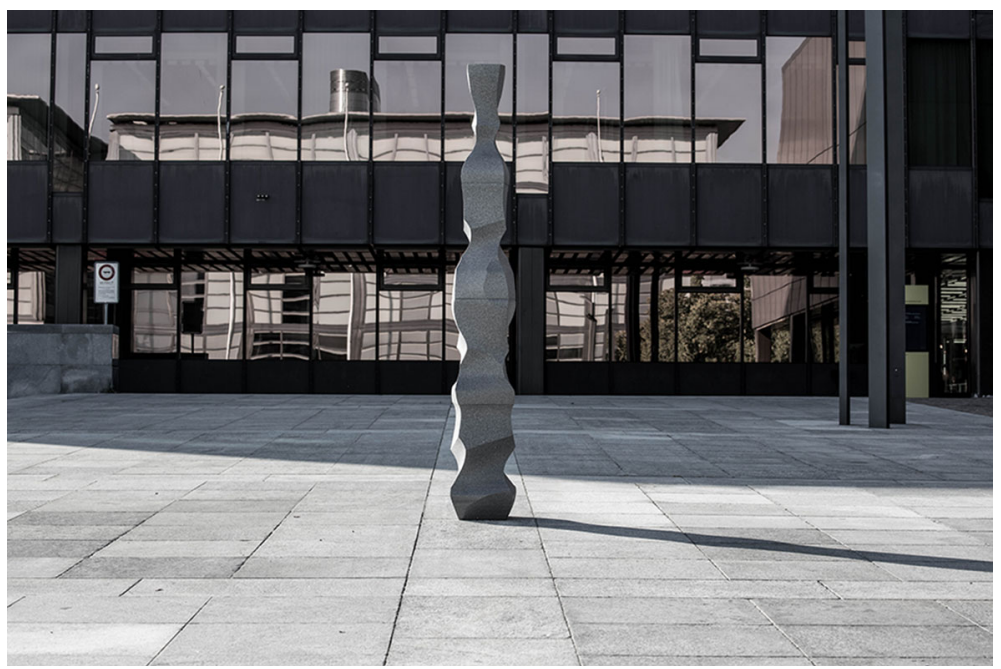

Fig. 1 Image showing the work of a group of participants at the Force-Adaptive Hot-Wire Cutting workshop at AAG2016. Photo: Gramazio Kohler Research, ETH Zurich, 2016, reproduced by permission 


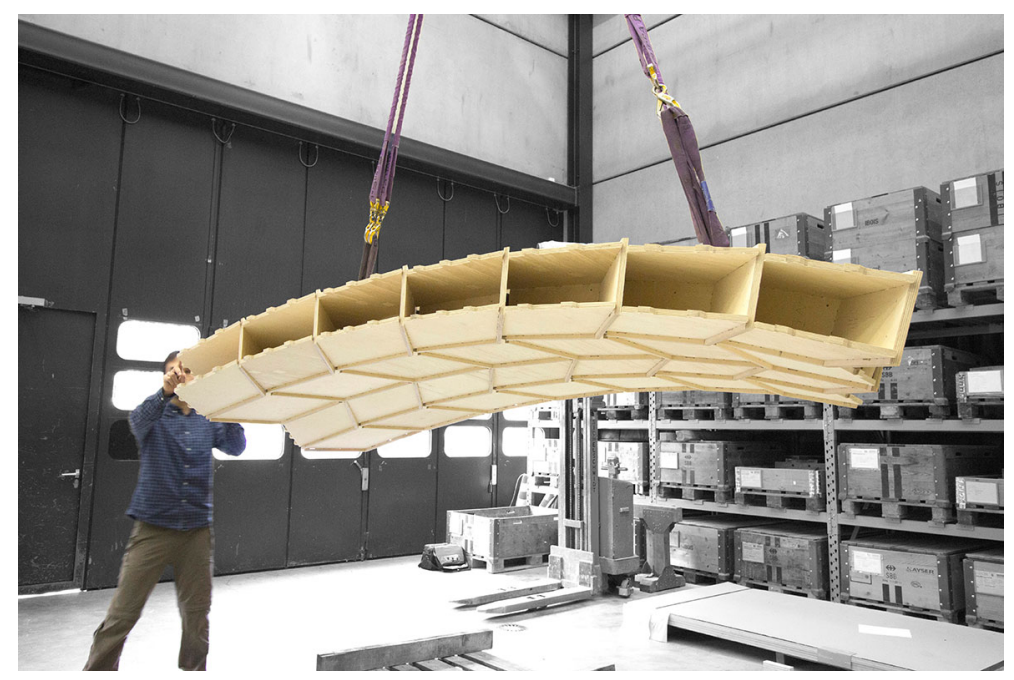

Fig. 2 Image from the paper "A Double-Layered Timber Plate Shell" presented at the AAG2016 conference. This $8 \times 7$ segment prototype was fabricated from $15 \mathrm{~mm}$ birch veneer panels at a scale of 1:2.6. The completed prototype was exhibited during AAG2016. Photo: Laboratory for Timber Construction (IBOIS) and Computer Graphics and Geometry Laboratory (LGG), EPFL, 2016, reproduced by permission

mechanical properties of the thin plywood sheets employed for the fabrication process.

The first session on the second day was chaired by Philippe Block and demonstrated projects with novel design, optimisation and fabrication methods for building complex patterns and free-form or transformable structures, by integrating design and construction constraints into a seamless workflow. Aleksandra Anna Apolinarska introduced a cross-disciplinary computational workflow developed and implemented in the recently completed "Sequential Roof" project at ETH Zurich, a robotically-assembled load-bearing free-form timber structure (Fig. 4).

Participants were offered guided tours to see the roof structure in person and gain insight into the production and assembly processes. Chaired by Paul Nicholas, the following session highlighted novel design and pre-processing of geometries for digital fabrication methods, such as robotic hot-wire and hot-blade cutting. The final session was chaired by AAG initiator Helmut Pottmann and showcased recent research on the computational design and fabrication of freeform shell structures. Matthias Rippmann presented the development and building of an unreinforced freeform vault shell structure made of thin discrete limestone blocks that are spanning more than 15 meters in pure compression without any mortar between the blocks (Fig. 5). Their work "The Armadillo Vault" was exhibited at the 15th Venice International Architectural Exhibition.

The two best paper awards were presented to Caigui Jiang, Felix Günther, Johannes Wallner, and Helmut Pottmann for their paper "Measuring and Controlling Fairness of Triangulations", and to David Brander, Andreas Bærentzen, Kenn Clausen, Ann-Sofie Fisker, Jens Gravesen, Morten N. Lund, Toke B. 
a

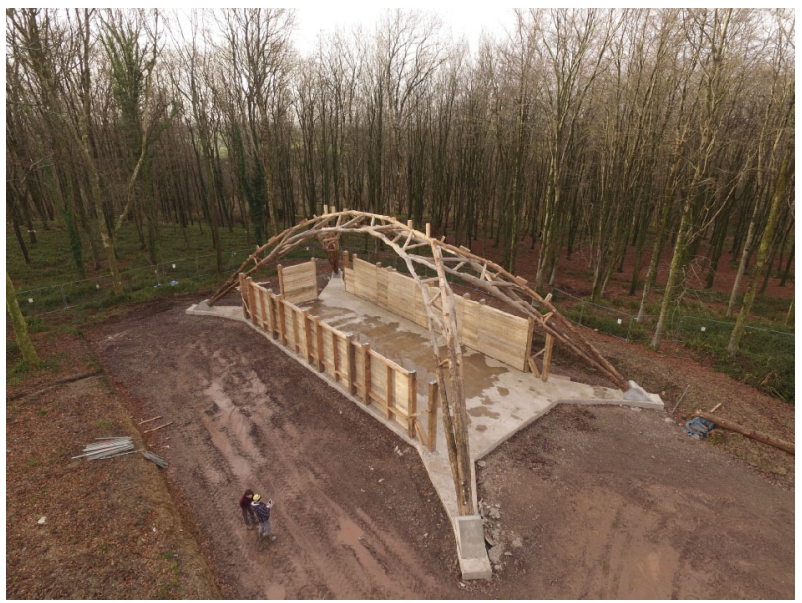

b


$8 \mathrm{~A} 03$ $8 \mathrm{~A} 12$

$8 \mathrm{~A} 13 \quad 8 \mathrm{~A} 14$ $8 \mathrm{~A} 20 \quad 8 \mathrm{C} 05$

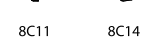

$8 \mathrm{D} 02 \quad 8 \mathrm{D} 03$

9F09

$9 \mathrm{G} 15$

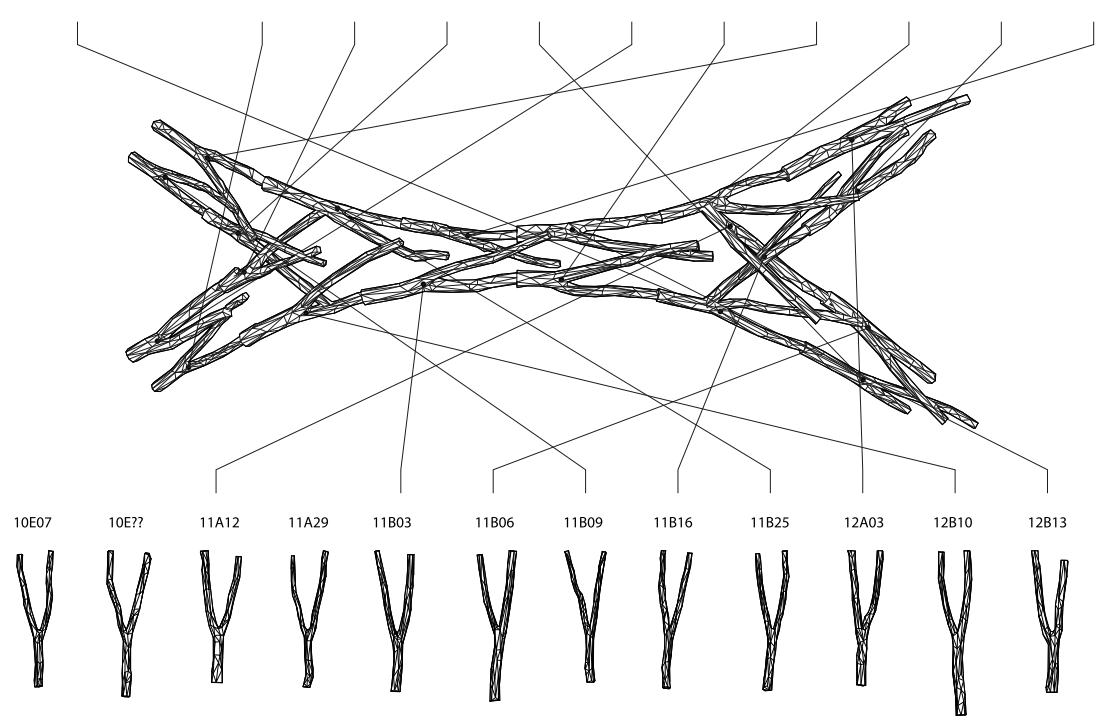

Fig. 3 Images from the paper "Tree Fork Truss: Geometric Strategies for Exploiting Inherent Material Form" presented at the AAG2016 conference. a This aerial photograph shows the completed truss for the Wood Chip Barn project at Hooke Park; b 204 tree forks were photographically surveyed, analysed, and matched to the structural geometry to produce the arching truss. Photo and image: Architectural Association (AA), 2016, reproduced by permission 


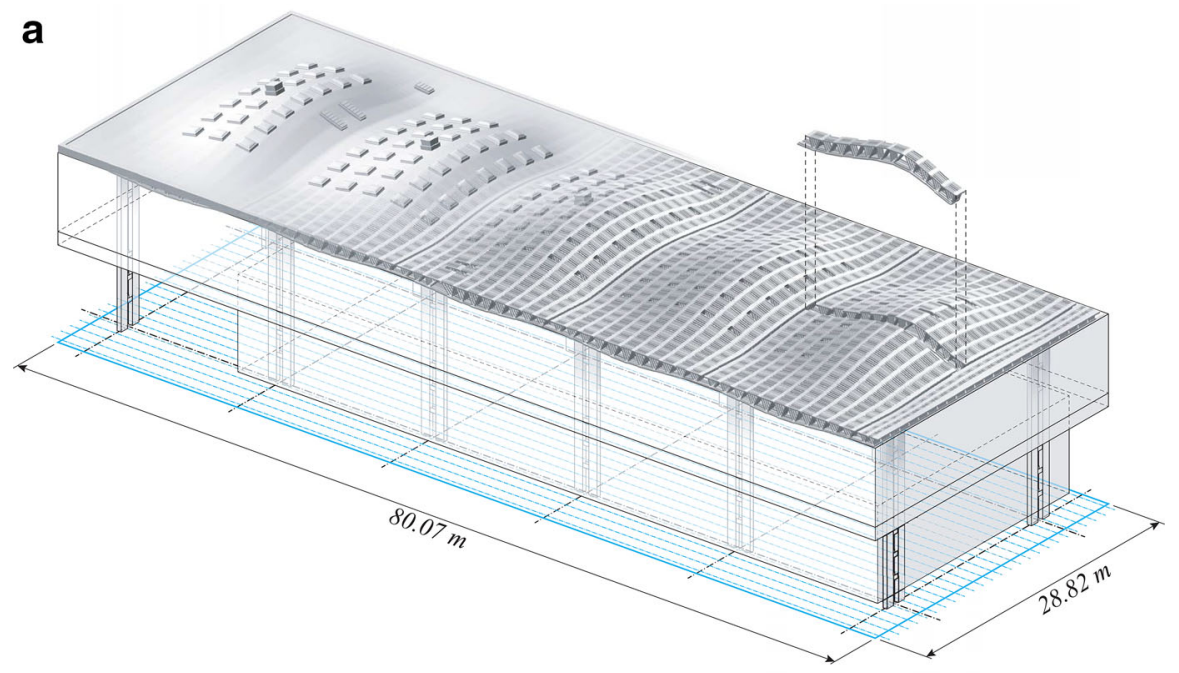

b

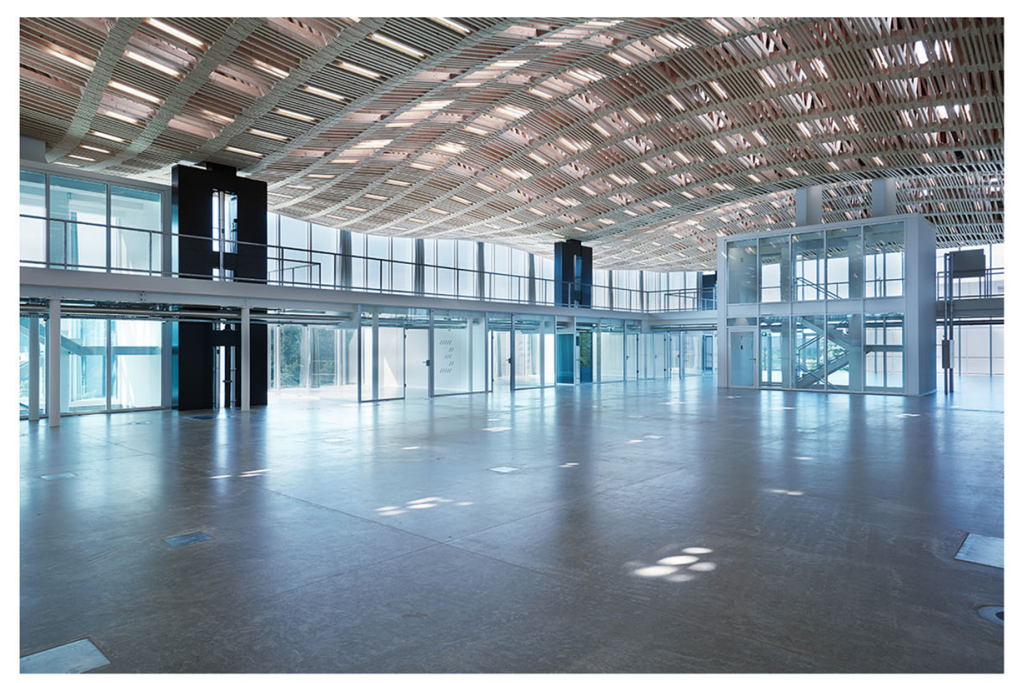

Fig. 4 Images from the paper "Mastering the 'Sequential Roof" presented at the AAG2016 conference. a Isometric overview of the roof. It is composed of 168 timber trusses supported by a primary steel structure. Image: Gramazio Kohler Research, 2016; b Interior view of the completed roof. Photo: Andrea Diglas/ITA/Arch-Tec-Lab AG, ETH Zurich, 2016, reproduced by permission

Nørbjerg, Kasper Steenstrup, and Asbjørn Søndergaard for their paper "Designing for Hot-Blade Cutting: Geometric Approaches for High-Speed Manufacturing of Doubly-Curved Architectural Surfaces" by the scientific co-chairs Sigrid Adriaenssens, Achim Menges, and Mark Pauly.

In addition to the presentations of peer-reviewed papers, the conference featured a panel on strategies for the teaching of geometry in architecture hosted by Robert 




Fig. 5 Image from the paper "The Armadillo Vault" presented at the AAG2016 conference. The completed work was presented in the Corderie dell'Arsenale at the 2016 Architecture Biennale in Venice, Italy. Photo: Iwan Baan. Block Research Group, ETH Zurich, 2016, reproduced by permission

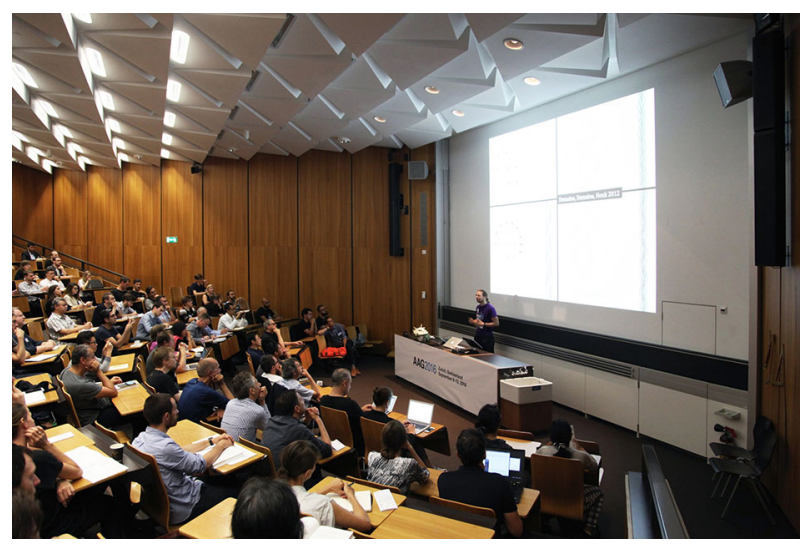

Fig. 6 Image taken during the keynote lecture by Erik Demaine at the AAG2016 conference. Demaine gave the audience insight on his form-finding processes, and showed examples from his folding and origami works with paper, plastic and glass. Photo: NCCR Digital Fabrication, 2016, reproduced by permission

Aish, and four high-profile keynote lectures by Urs B. Roth, Erik Demaine, Werner Sobek, and Lord Norman Foster and Francis Aish of Foster + Partners (Fig. 6).

The lecture by Foster and Aish was held at the recently opened Robotic Fabrication Laboratory (RFL) at ETH Zurich. The new facility is the world's first research platform for large-scale robotic fabrication in architecture. About 500 participants attended the keynote lecture. Foster and Aish jointly presented the development of their Mexico City International Airport project, intended to become one of the world's largest airports, which is planned to be entirely enclosed within a continuous lightweight gridshell (Fig. 7). 


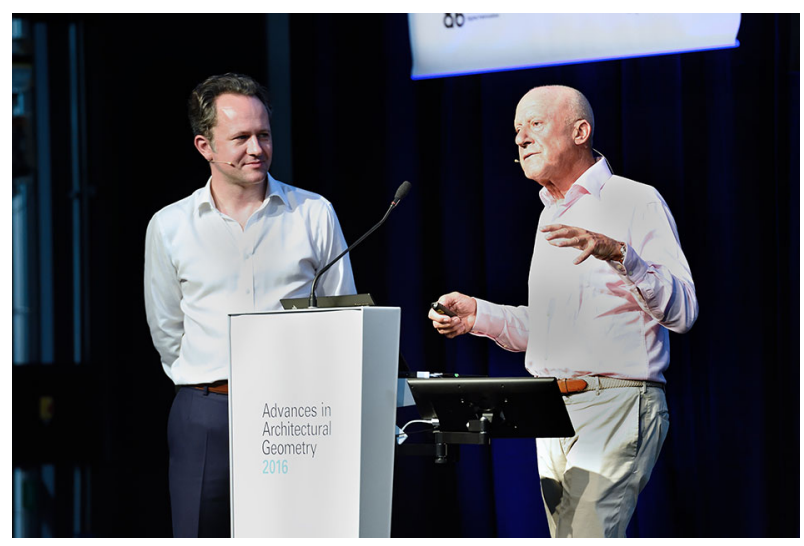

Fig. 7 Image taken during the keynote lecture by Norman Foster and Francis Aish at the AAG2016 conference. More than 500 participants joined the keynote lecture held at the Robotic Fabrication Laboratory (RFL) at ETH Zurich. Photo: NCCR Digital Fabrication, 2016, reproduced by permission

Another significant highlight of the symposium was the accompanying exhibition on current projects in architectural geometry that featured works by conference keynotes Urs B. Roth and Erik Demaine as well as works by research groups from ETH Zurich, EPF Lausanne, and TU Munich, some of which had been presented during the conference (Fig. 8).

With more than 300 participants from various companies and institutions from all over the world, the AAG symposium once again proved to be a unique facilitator for the dissemination of innovations in the field of architectural geometry. The AAG

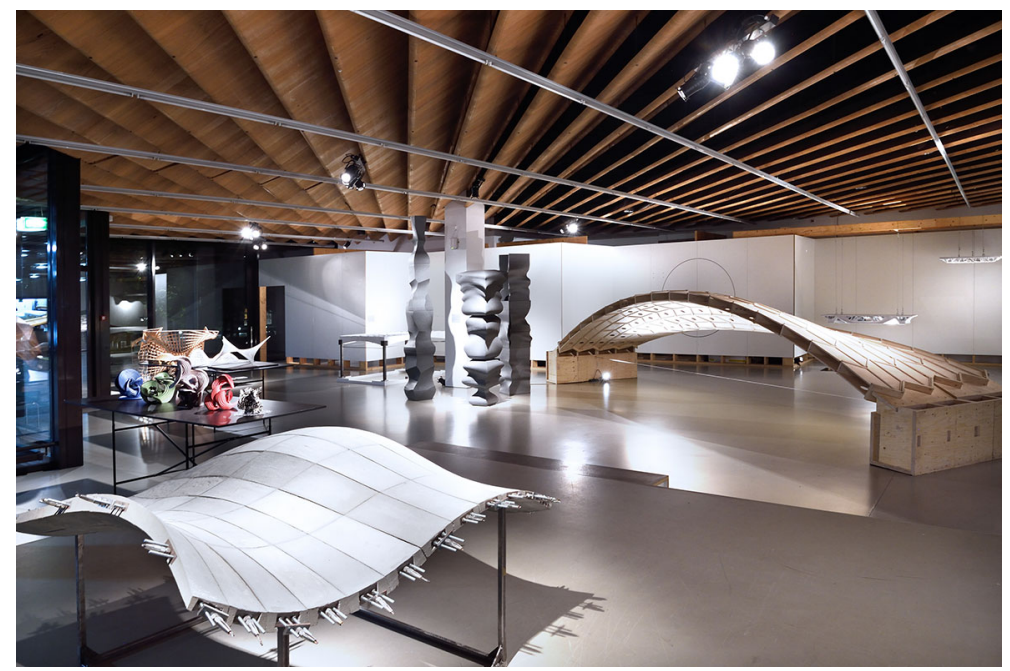

Fig. 8 Image from the AAG2016 exhibition. The exhibition highlighted current developments at the intersection of applied geometry and architecture. Photo: NCCR Digital Fabrication, 2016, reproduced by permission 
community is now already looking forward to AAG2018 which is planned to take place at Chalmers University of Technology in Gothenburg, Sweden, in 2018.

Further details about AAG2016 can be found on the symposium's website http:// www.aag2016.ch. The AAG2016 proceedings are available as an open access e-book at http://vdf.ch/advances-in-architectural-geometry-2016-e-book.html.

Orkun Kasap studied architecture in Turkey, Denmark, and Switzerland between 2004 and 2012. After receiving his MSc in Architecture from ETH Zurich, he joined the Chair of Architecture and Digital Fabrication at ETH Zurich where he worked as a research assistant. Since 2014, he works as project coordinator at the National Centre of Competence in Research (NCCR) Digital Fabrication in Switzerland. Orkun was responsible for the coordination of the Advances in Architectural Geometry (AAG) 2016 Symposium and the preparation of its proceedings. 